\title{
Publisher Correction: Orthogonal regulation of DNA nanostructure self-assembly and disassembly using antibodies
}

\author{
Simona Ranallo, Daniela Sorrentino \& Francesco Ricci(D)
}

Correction to: Nature Communications https:/doi.org/10.1038/s41467-019-13104-6, published online 03 December 2019.

The original version of this Article contained an error in the legend of Fig. 4b. The text for Fig. $4 \mathrm{~b}$ which should be "Fluorescence confocal microscopy images of nanotubes in the absence of both antibodies (left), after addition of anti-DNP antibody (300 nM) (center) and after the addition of anti-Dig antibody $(300 \mathrm{nM})$ (right)" was incorrectly given as "b Fluorescence confocal microscopy images of nanotubes in the absence of both antibodies (left), after addition of anti-Dig antibody (300 nM) (center) and after the addition of anti-DNP antibody (300 nM) (right)." This has been corrected in both the PDF and HTML versions of this Article.

Published online: 13 January 2020

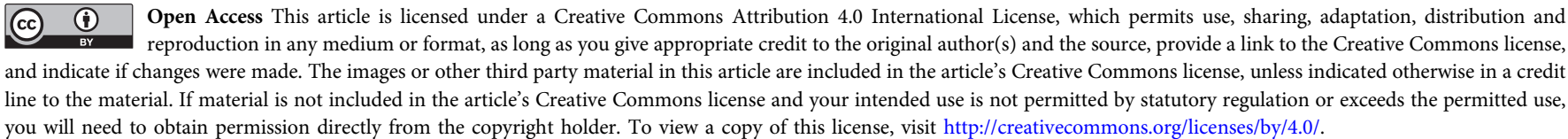

(c) The Author(s) 2020 